\title{
TERAPÊUTICA ODONTOLOGICA VETERINÁRIA COM FITOFARMACOS
}

\author{
Thays de Carvalho Amorim 1 \\ Yasmini da Silva Schunk ${ }^{2}$ \\ Lais Regina Ferreira Magnago ${ }^{3}$ \\ Cinthya Brillante Cardinot ${ }^{4}$ \\ Felipe Berbari Neto ${ }^{5}$ \\ Zelia Gai Teresinha ${ }^{6}$ \\ Marcos Santos Zanini ${ }^{7}$ \\ Lenir Cardoso Porfírio ${ }^{8}$
}

Resumo: A saúde oral é essencial para a sanidade e bem estar dos animais de companhia. A doença periodontal é grave e associada a elevados níveis de dor, em consequência pode ocasionar enfermidades sistêmicas, dentre elas, a endocardite, glomerulonefrite, hepatite, alterações pulmonares e meningite. Em busca de métodos alternativos para melhorar a saúde oral e consequentemente a qualidade de vida dos animais, utilizou-se o extrato hidroalcoólico a $20 \%$ de romã como tratamento profilático para problemas bucais de cães. Na avaliação in vitro, do extrato de Punica granatum (romã) em placas semeadas com microbioma oral de cães, foi possível observar, que o extrato da romã apresentou halos de inibição de 10 a $14 \mathrm{~mm}$. Como demonstrou atividade antimicrobiana, o extrato foi utilizado no preparo de formulação fitoterápica em gel dentário e colutório para higienização da cavidade oral de 10 cães adultos e sem raças definidas, no período de dois meses. Observou-se que houve diminuição das placas dentárias e do mau hálito com o uso do gel dentário. O colutório não apresentou receptividade na aplicação do produto pelos animais.

Palavras-chave: Doença periodontal; Cães; Placa bacteriana; Dente.

\footnotetext{
${ }^{1}$ Medicina Veterinária/Universidade Federal do Espírito Santo, Brasil. E-mail: mv.thaysamorim@gmail.com.

2 Medicina Veterinária/Universidade Federal do Espírito Santo, Brasil. E-mail: yasmini.schunk@hotmail.com.

${ }^{3}$ Medicina Veterinária/Universidade Federal do Espírito Santo, Brasil. E-mail: lais.magnago@hotmail.com.

${ }^{4}$ Medicina Veterinária/Universidade Federal do Espírito Santo, Brasil. E-mail: cinthyabri@gmail.com.

${ }^{5}$ Medicina Veterinária/Universidade Federal do Espírito Santo, Brasil. E-mail: berbarineto@hotmail.com.

${ }^{6}$ Medicina Veterinária/Universidade Federal do Espírito Santo, Brasil. E-mail: gauchadealegre@yahoo.com.br.

7 Medicina Veterinária/Universidade Federal do Espírito Santo, Brasil. E-mail: zaninims@gmail.com.

${ }^{8}$ Medicina Veterinária/Universidade Federal do Espírito Santo, Brasil. E-mail: lenircp52@gmail.com.
} 